\title{
Selling Product or Selling Gender: Toy Advertisements and Child
}

\section{Gender I dentity}

by Lauren Andreu

\begin{abstract}
Significant research has been conducted on how well children understand advertisements and the effect advertisements and television have on a child. However, there is not a large amount of research on the relationship between toy advertisements, specifically, on children's choices for play and on gender identity. This paper will attempt to bring together multiple aspects of research that touch on all of these points to better grasp a full understanding of the topic. The current study consisted of three phases: (1) a series of interviews with children ages four to nine, (2) a survey of parents, and (3) in-store observation. The research found that young children identify certain toys as gendered but that they and their parents are open minded about playing with many toys specifically marketed to the opposite gender. It was also found children could not provide a true understanding of what an advertisement's purpose is until they were nine years old.
\end{abstract}

\section{Introduction}

The average American child is exposed to more than 25,600 television advertisements alone per year (Common Sense Media/ Holt). Currently, there are no methods to effectively measure how many advertisements an American child sees because of the multiple ways children are now being advertised to. Phone screens, billboards, buses, bus stops, radio, and computer screens are just a few of the ways advertisers can reach the consumer. The consumer does not just have to be the purchaser of the product, but can also be someone who will ask for the product to be purchased. Advertisements geared at children do exactly this. Children do not generally 
have the means to buy the toy that they want so they rely on their parents or another adult to provide it for them.

Advertising targeted to children has ethical implications. There are numerous laws and regulations guiding when children can be advertised to on television and how much they can be advertised to. Despite these laws and regulations, children are still one of the largest markets for advertisers and they manage to find a way to tap into this purchasing power (Erwina, 2014). Some of these laws and regulations have been put in place because of the influences advertising has on a child (Beales, 2004). One of these influences may be gender roles and identity.

When it comes to sex and gender many people refer to the nature versus nurture argument. Francis Galton developed the nature versus nurture argument in the late $19^{\text {th }}$ century (McLeod, 2007). Physical traits are easy to pinpoint. We understand how they develop and where they come from. Personality traits are more abstract though. When a human being is born do they inherently know that pink is a girl color and blue is for boys? Is it already determined that they will be introverted or extroverted? Or do life experiences play the major role in determining who people are and what they come to believe and form opinions about. Social learning theory and cultivation theory play a major role in demonstrating that it is nurture not nature that influences these personality traits. Stimuli for change can come from parents, friends, teachers, family members, coworkers, advertisements, movies, toys, and so much more. This paper will focus on toy advertisements and the relationship to child gender identity. The goal of this research is to understand how children react to toy advertisements, how they select toys, and whether or not gender has an influence on these opinions and choices. 


\section{Review of the Literature}

\section{Understanding of Gender}

In Bakir and Palan's literature review, they mark four different stages in gender development. The different stages were originally marked by Hanns Martin Trautner in his 1992 article "The Development of Sex-Typing in Children: A Longitudinal Analysis." The first stage is awareness and occurs between ages three and below. At age three children begin to identify gender stereotypes (Blakemore \& LaRue, 1979). There is not a consensus as to the age at which children can categorize male versus female. Walsh, Katz and Downey's 1991 study says it is as early as six months (as cited in Bakir \& Palan, 2010), but Leinbach and Fagot's 1993 study and Miller, Young and Morse's 1982 study indicate it is not until later years (as cited in Bakir \& Palan, 2010). The second stage is rigidity and occurs between four and seven years of age. In this stage children's understanding of gender stereotypes become stronger and they begin to understand "that biological sex is constant and cannot be altered by changing hairstyles, clothing, or other personal attributes ... children systematize their behavior according to female and male gender roles, with an understanding that 'appropriate' gender behavior is valued more than 'inappropriate' gender behavior" (Bakir \& Palan, 2010, 37). At the third and fourth stages, flexibility begins between eight and eleven and then increases even more in early adolescence. During this stage children become more understanding and open minded about gender roles and what one's gender identity may mean. It is important to understand how gender identity develops to understand how a child will receive gender roles in advertising. 
Gender in Advertising for Children's Toys

"One aspect of advertising that may play a significant role in how a child responds to a television advertisement is the degree to which the execution of the ad evokes his or her understanding of gender, that is, the degree to which the ad makes gender salient to the child" (Bakir \& Palan, 2010, 35). Child advertisements reinforce gender stereotypes in the way the children are portrayed. Males are a more common voiceover (Martinez, Nicolas, \& Salas, 2013; Browne, 1998). In commercials directed at males the toys and the boys are depicted as more aggressive, loud, competitive, and exciting (Bakir \& Palan, 2010; Blakemore \&Centers, 2005; Browne, 1998). In commercials directed toward females the toys tend to emphasize beauty, domesticity, and nurturing skills (Blakemore \&Centers, 2005).

Bakir and Palan found that "children responded more favorably to ads with 'gendered' characters"' $(2010,41)$, meaning they preferred two girls or two boys to be together in the ads. They also found that children did not respond positively to male characters being placed in an ad for a female product (2010). As Bakir and Palin discovered, gender needs to be pronounced to help the child understand his or her gender identity. Understanding of gender plays a critical role in advertising preferences. In addition to knowing how children understand gender and what gender identity means for advertisements, it is also important to understand how well children really comprehend advertisements.

\section{Advertising Understanding}

Much of the controversy surrounding advertising to children comes from theories of child psychologists and consumer researchers who claim that young children do not 
really understand that the intention of advertising is to persuade, but instead view it as "informative, truthful, and entertaining" (J ohn, 1999, 3). Research has found that children were able to identify a commercial by the age of five and sometimes even four but identification does not necessarily lead to comprehension (Butter, Popovich, Stackhouse \& Garner, 1981; J ohn, 1999; Levin, Petros \& Petrella, 1982). Butter et al.'s study found that "while preschool children can tell the difference between a program and commercial, they do not necessarily understand the purpose of the two. Young children may know they are watching something different than a program, but do not know the intent of what they are watching is to invite purchase of a product or service" $(1989,56)$. It is not until about seven or eight years old that children understand the persuasive effects of advertising (J ohn, 1999; Levin et al., 1982). Next, we will explore some important theories that have been developed to help understand behavior and learning to see the relationship between learning, behavior, and our current culture.

\section{Influential Theories}

Pike and J ennings (2005) bring together cultivation and social learning theory to claim that if the media acts as a socializing agent, it may also influence how our culture constructs and maintains gender identity. Gerbner and colleagues developed cultivation theory, which is the belief that "heavy television viewing tends to cultivate attitudes towards the social world that are based on the world represented onscreen. The mass media act as a socializing agent, cultivating values which are already present in culture" (Chandler \& Munday, 2011). This means that the more television a person watches the more likely he or she is to develop the same set of beliefs as the characters displayed on screen. Bandura developed social learning theory, which suggests that individuals learn 
through watching and then imitate this behavior in their own lives. This learning does not have to be solely through the media but can occur from watching other individuals such as a parent or teacher. People learn acceptable and non-acceptable behavior by observing what type of behavior is reinforced or punished. Pike and J ennings (2005, p. 84) mark that children develop role models through television characters and therefore it "makes television one of the most important teachers of gendered behavior."

\section{Toy Industry}

The three top toy brands globally are Mattel, LEGO, and Hasbro. Sales for 2013 were not remarkable for Mattel or Hasbro but strong for LEGO. However, Mattel is the number one manufacturer. The traditional toy industry is suffering due to an increased interest in electronics and age of play decreasing amongst children (Erwina, 2014). "Ads for traditional toys and games mainly entail television spots that are also largely integrated with other advertising mediums, such as print advertising, catalog, radio, and movies. Social media is also increasing its presence" (Erwina, 2014). Since television is the largest venue to advertise traditional toys, the research will look at these types of advertisements. Television may be the most common medium because of the large number of children that are exposed to television on a daily basis.

"Marketing of traditional toys and games typically has three main approaches: targeting parents to purchase the product for their children; targeting children to use their pester power to convince their parents to buy the product; or particularly with older children, targeting children directly to buy the product for themselves" (Erwina, 2014). This is important in understanding who makes purchasing decisions and who has purchasing power within the industry. While children do have pestering power, they do 
not have any money to actually purchase toys so parents have a large influence in what toys are actually obtained. According to Mintel's research, the top purchase influencers of toys (see Figure 1) are television commercials (31\%), family/ friends (31\%), children (29\%), and window shopping (28\%) (Erwina, 2014). When the adult purchaser of traditional toys has children under the age of 18 in the household television commercials are the largest influences; but, when adults did not have children under the age of 18 in the home they relied on friends/family for recommendations.

Information sources that are influential to traditional toys and games purchases, February 2014 "How do you typically learn about the traditional toys and games that you end up buying?"

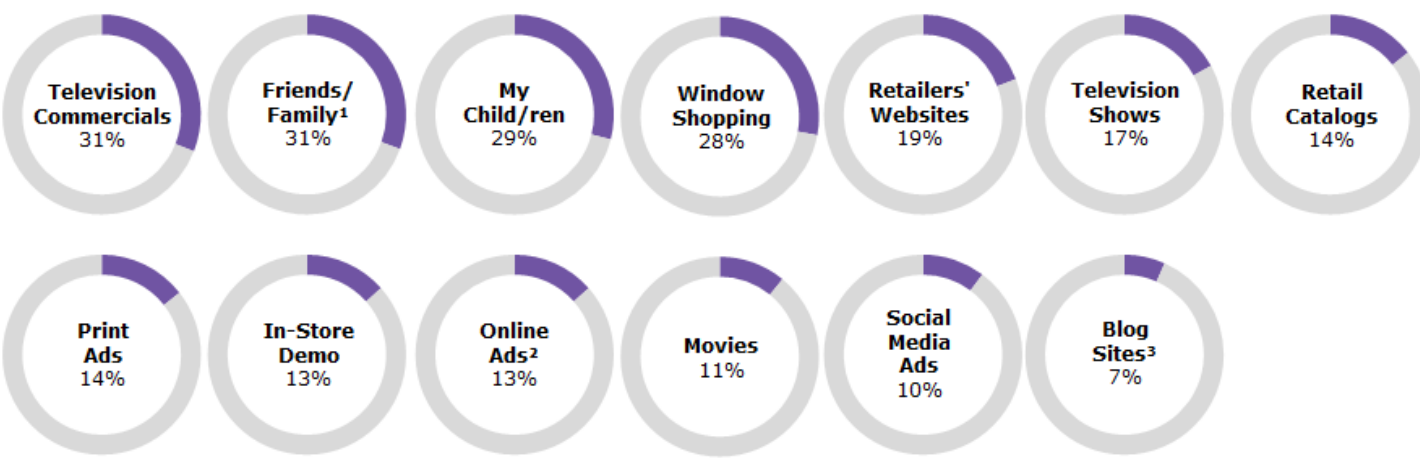

Base: 1,268 internet users aged 18+ who have bought traditional toys and games in the last 12 months

1 "recommendations from friends/family or blog sites"

2 "online advertisements (excluding social media sites)"

3 "recommendations from blog sites"

Source: Mintel

Figure 1: Information sources that are influential to traditional toys and games purchases, February 2014 


\section{Methodology}

The research consisted of three phases. Phase 1 included seven interviews of children aged four to nine years old. Interviews lasted approximately 45 minutes and were conducted between August 2015 and October 2015. Of these seven interviews, four respondents were male and three respondents were female. All of the names of the respondents have been changed to protect their privacy. Respondents were: Mark- nineyear-old male, J ane- seven-year-old female, Olivia- nine-year-old female, Max- sevenyear-old male, Nate- five, but almost six-year-old male, J ake- five-year-old male, and Sarah- four-year-old female.

Phase 2 included a Qualtrics survey of male and female parents of children aged four to nine years old. The survey was distributed online through social media in August 2015. A total of 92 surveys were started with 59 being qualified completes. We will only focus on these completed 59 surveys $(n=59)$. Fifty-eight respondents were female, one choose not to answer. Sixty-nine percent of the respondents were between the ages of 35 and 44 .

Phase 3 included observational research at different toy retailers in the Dallas-Fort Worth (DFW) area. The purpose of this research was to observe the set-up, display of their toy sections, and the packaging of the different products.

Research Questions, Objectives, and Hypothesis

H1: Parents will claim they do not heavily monitor their child's gender identity and that television-viewing rates will be high.

Objective 1: To understand the correlation between advertising of toys and child gender identity. 
RQ1_1: What influence does advertising have on a child's gender identity?

RQ2_1: At what age do children begin recognizing a difference between boy and girl toys in advertising?

RQ3_1: What are the different components shown in gender-specified advertisements? Objective 2: To understand how parents and guardians make purchasing decisions for their children's toys.

RQ1_2: What influence do parents' beliefs about gender identity have on their purchasing behavior for their children?

RQ2_2: How do religious, geographical, and generational beliefs affect parental beliefs?

RQ3_2: Do parents refuse to buy their child certain toys if they do not correspond with the child's gender?

Objective 3: To understand a four to nine year old's understanding of gender.

RQ1_3: To a child, what defines a person as male or female?

RQ2_3: Why do children of each gender select particular toys over others?

RQ3_3: Do children notice packaging when making their toy selections?

RQ4_3: What influence do siblings play on a child's view of gender appropriate toys?

RQ5_3: Does the amount of television watched by children affect their toy choices?

RQ6_3: In the child's opinion how do they decide what toys they want?

Objective 4: To evaluate store set-up and display for toys and its relationship to gender stereotypes.

RQ4_1: Do stores reinforce the concept of "boy toys" and "girl toys"? 


\section{Participants}

Phase 1 participants were male and female children aged four to nine. Phase 1 participants were recruited through convenience and snowball sampling. Parents of children between the ages of four and nine were asked directly if they would be interested in having their child participate in the study. If parents showed an interest in having their child participate, I then set an appointment with the parents to conduct the interview with their child. Prior to conducting the interview, I made sure the child was interested in participating as well. I posted on different Facebook groups such as Tangelwood Buy/ Sell, Delta Gamma Alumnae, and Gamma Tau Alumnae asking if people would be interested in an interview. After an interview was conducted, I asked the parents if they had any friends that they thought would be interested. While I did get some interest from parents in other locations I decided to pick families in the DFW area for convenience purposes. I also asked families my friends or I knew from babysitting if they would be interested.

Phase 2 participants were parents who had at least one child between the ages of four and nine. Phase 2 participants were recruited through convenience sampling and snowball sampling. The survey was posted on the social media platform Facebook. It was posted on my own Facebook page as a status several times. I also utilized the same Facebook groups as mentioned above to post the survey. Surveys were emailed to family and friends that had children in the correct age group. At the end of the survey, I asked participants to share the survey on their own social media pages. It was made clear that there would be no penalty if potential participants decided not to partake in the study or decided to withdraw at any point. Survey participants needed to have one child between the ages of four and nine. A majority of the Phase 2 respondents were from Texas. 


\section{Procedure}

Phase 1 interviews were conducted in the child's home. Parents signed appropriate paperwork, including informed consent forms (see Appendix C) and the child gave a verbal agreement. An interview guide (see Appendix B) was utilized to guide the interview. The order of the advertisements shown was rotated. All participants of the same gender in the interviews were shown the same advertisements (see Appendix D). There was one variation based on child gender. The advertisements were either for the exact same products that the child would then be asked to select, or for a very similar product. The toys included Playmates Toys Teenage Mutant Ninja Turtles Half-Shell Heroes Ralph with Minibike (TMNT Figure), Hasbro Nerf Rebelle Bliss, Hasbro Ultimate Spider-Man Web Warriors (Spider-Man Figure), Mattel Barbie Fashionastas, LEGO Friends Little Foal, LEGO Creator Emerald Express, and Hasbro Play-Doh. These toys were selected because they were all around the same price range of three to ten dollars and where they would fit in with my coding mechanism. The pairings went as followed: LEGO Creator and LEGO Friends, Barbie and Spiderman, if male Nerf Rebelle and Play-Doh and if female TMNT figure and Play-Doh.

Play-Doh was coded as gender neutral. Nerf Rebelle, Lego Friends, and Barbie were coded as female toys. Lego Creator, Spiderman, and TMNT figure were coded as male toys. I selected Nerf Rebelle because a Nerf gun is a traditionally male-targeted toy, but in 2013 Hasbro released the Nerf Rebelle line (Busis, 2013) to be marketed toward girls. I wanted to find a toy that was originally meant for girls but then marketed toward boys but struggled to find an equivalent product. This, likely, is due to the cultural perception that it is less acceptable for boys to play with traditionally feminine toys than it is for 
girls to play with traditionally masculine toys (Fisher-Thompson \& Sausa, 1995; Martin, 1990; Freeman, 2007).

Phase 2 was created in Qualtrics and distributed on social media sites, such as Facebook. Check Appendix B for the interview guide.

In Phase 3, I visited three different toy retailers including Wal-Mart, Target, and Toys "R" Us. This is a very small sample of toy retailers and does not mean that all of these retailers use the same displays in other locales. My intention of going to the toy stores was to get a general understanding of the shopping experience when it came to toys. I wanted to understand what children were exposed to, what parents were exposed to, and how the products were presented. These three retailers were selected because of their proximity to my residence, as well as their popularity among toy purchasers (Erwina, 2014). Sixty percent of toy purchasers buy at a mass-merchandiser like WalMart or Target, and 40\% shop at a toy-specialty store like Toys "R" Us (Erwina, 2014).

\section{Results}

Television

According to survey results, age was a stronger predictor of the amount of time spent watching television than was gender. This may be due to the child not being in school for as many hours and not having as many extra-curricular activities. Mintel's report mirrors these results saying, "kids express mixed feelings about watching TV; while $76 \%$ say they love watching TV,' $50 \%$ say watching too much TV is 'bad for you.' Younger kids are more likely than older kids to say they love watching TV, which suggests that as kids get older, they pursue other activities and become slightly less interested" (Bonetto, 2015). 
Television was typically accessed either through cable or Netflix (see Figure 2). With Netflix there are no commercials for the child to watch but it is unclear of whether or not this is a factor in why Netflix is the selected vehicle.

\section{Media Used to Watch Television}

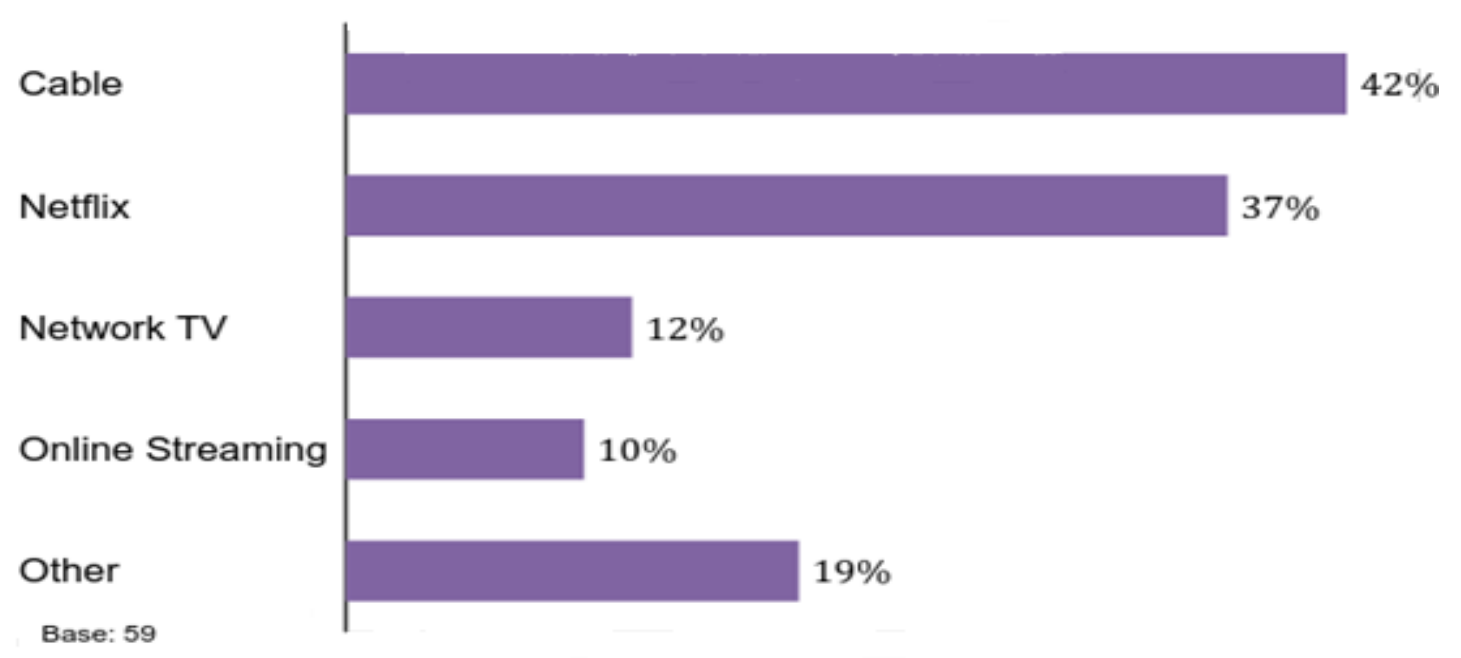

Figure 2: Media Used to Watch Television

In addition to where children watch television shows, it is important to recognize how much television they are also watching. "Kids spend an average of 2.2 hours watching TV on weekdays and 3.6 hours on weekend days" (Bonetto, 2015). This indicates that television is a popular medium and activity amongst children (see Figure 3) and can be very influential on a child. Cognitive and social learning theory address how the amount of television watching may affect behavior and that children will mirror the characters they frequently see.

According to the survey $(n=72)$, the most popular television shows for children are Paw Patrol (14\%), Curious George (13\%), Odd Squad (13\%), Teenage Mutant Ninja Turtle (10\%), and Wild Kratts (10\%). All of these shows are marketed directly toward children, are animated, and are aired on popular child networks such as NickJ r., PBS 
Kids, and Nickelodeon. This provides advertisers who are trying to reach children a clear path of how to reach this target market.

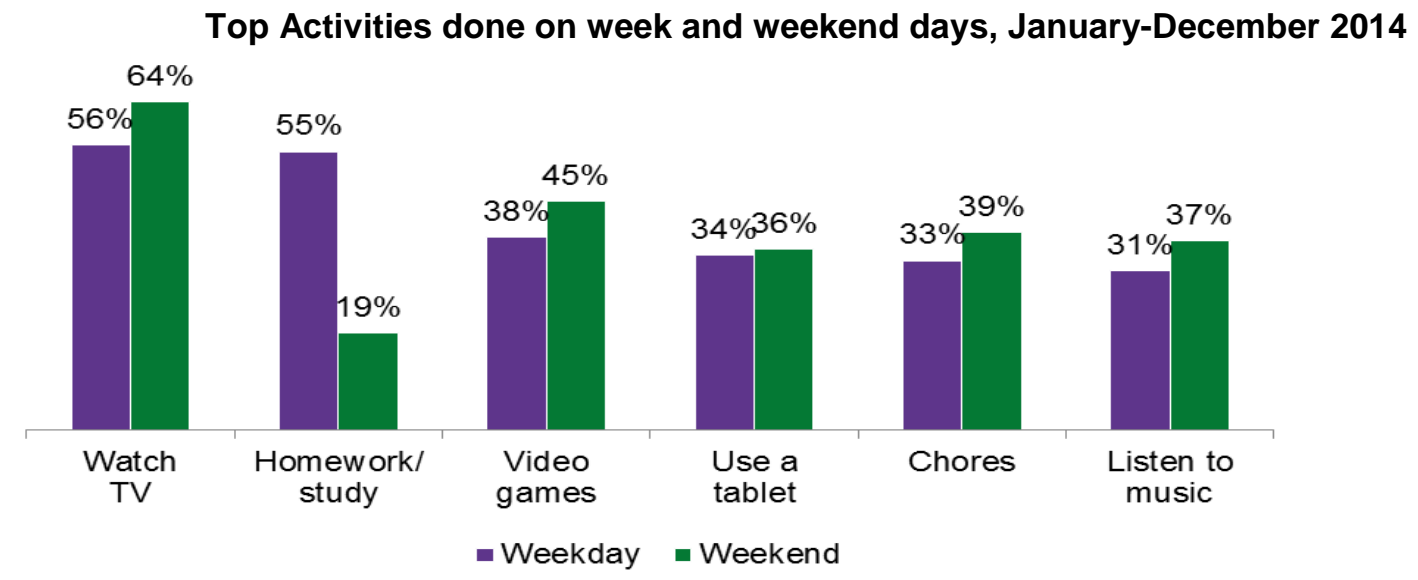

Base: 2,235 kids aged 6-11

Source: C+R Research YouthBeat ${ }^{\mathrm{TM}}$. Data collected from January to December 2014/Mintel

Figure 3: Top Activities done on week and weekend days, January-December 2014

\section{Ability to Identify a Commercial}

In line with prior research (J ohn 1999; Levin et. al., 1982), participants at age nine were best able to understand the persuasive intent of advertising. The younger children, including the seven year olds, knew they interrupted their show, but could not give a detailed definition of why they are shown. They knew commercials were shown in between their television shows, but could not explain that they were persuasive in nature.

\section{Toy Selection}

According to the survey done in Phase 2, gender and age did not affect the likelihood that the child would have toys that they were not allowed to play with: 36 percent of 
respondents said that their child does have toys they are not allowed to play with, 44 percent said their child does not have toys they are not allowed to play with, and 20 percent said they were not sure. This indicates that there is not a strong trend amongst parents in blocking toy play. Despite the survey results, during the Phase 1 interviews no one said that their parents would care what toys they played with. Nate said they were not typically allowed to play with guns in his house, but this was the only restriction. Despite Nate's parents not allowing the children to play with guns, the parents said it was okay for the project. All seven children thought that their parents would be happy or not care if they played with cars, dolls, puzzles, or board games.

Children may not have felt restricted by their parents' point of view, but six were still able to identify toys as meant for a boy or a girl. They pointed out traditional stereotypes of color and what boys and girls would like to do with toys. Nate selected the LEGO Friends over the LEGO Creator because he likes animals and the LEGO Friends set has a horse. J ake selected the Nerf Rebelle but did say that it was meant for girls. Sarah selected the TMNT Figure over Play-Doh. She did not mark the TMNT figure as meant for boys and said that she sometimes watches the show with a male friend. When the two males selected the non-traditional gender toy, they gave a reason for their choices. Nate marked that he likes animals and that's why he wanted to play with the horse set, and J ake recognized that the Nerf Rebelle was for girls, but it may have seemed more fun to play with a Nerf gun since it is a traditionally male toy. While J ake was unable to articulate why he thought the Nerf Rebelle was meant for girls, it may be associated with the product's color and the commercial only featuring females. When looking at toys 
and commercials ${ }^{1}$, the children could tell if it was meant for a boy or girl based on the color of the product, who was in the commercial, and what the product actually was (LEGO, 2014; Nerf Rebelle Official, 2015; Playmate Toys, 2015; Toys R Us Singapore, 2014; Toys Videos, 2014; worldstoys, 2015).

\section{Identification of "Boy Toys" and "Girl Toys"}

While I did not ask the child to point out which toy was meant for girls and which toy was meant for boys, many of the children marked that boy toys and girl toys do exist in other commentaries. When I asked the children if their siblings played with their favorite toy the answer, if the child had a sibling of the opposite sex, was always no. Favorite toys by females with male siblings included Shopkins and American Girl. Olivia and J ane were the two female respondents with male siblings. Olivia's male siblings are 17 and 22 years old so this is likely the determining factor in why they do not play Shopkins with her. J ane's male sibling is six years old and does not like to play with her American Girl dolls because they are "girly" but her younger sister does like to play with the dolls.

Another area where boy toys and girl toys were marked was when the children were asked the following series of questions “Do girls play with toy cars? Do boys play with dolls? Do girls play with puzzles? Do boys play with board or card games?” In response to these questions, there was more flexibility for girls to play with toy cars than for boys to play with dolls. For example, J ane marked that girls do not typically like to play with toy cars but that she does, and Nate said that he doesn't really think girls would, but that

\footnotetext{
${ }^{1}$ The Barbie commercial used was removed from YouTube before citation. The video cited is the same product and shows the same important features as the original commercial.
} 
there is a girl at school who likes boy things so she may like toy cars. Nate's comment indicates that this girl may be a tomboy, but Nate did not have any negative feelings or judgments against the girl for being a tomboy. Other responses to girls playing with toy cars pointed out that boys do like to play with these and that girls may be scared of them. In response to boys playing with dolls, responses included that it had to be a boy doll, likely an action figure, that they would not like a doll because they like sports, that they may want to torture the doll to upset a sister, dolls are weird, or that they are too "fancy" for boys to want to play with. These responses depict classic stereotypes of boys as aggressive and athletic. None of the boys selected the Barbie doll to play with, but saw no issue with selecting the Spider-Man action figure. In fact, Max could hardly stand to watch the Barbie commercial when it played despite having a younger sister (worldtoys, 2015). When responding to the third and fourth question about toys that were coded as gender-neutral, responses indicated that the children thought boys and girls played with puzzles, board games, and card games.

In visiting stores that sell toys, I expected to see very clear segregation and signage demonstrating where to find the toys meant for boys and the toys meant for girls. WalMart was the only store that had overhead signs that said "Boy Toys" and "Girl Toys" but Target and Toys "R" Us did not mix toys that are meant for boys and girls; the aisles still separated the products relatively easily. A map of Toys " $\mathrm{R}$ " Us did indicate more clear gender separation by marking the traditionally girl toy sections in pink and the traditionally boy toy sections in blue. Gender-neutral toy sections were coded in colors like orange. Check Appendix E to see this map. 


\section{Likeability of Advertisements}

After I showed the child being interviewed a commercial, I asked if they liked the commercial and what they liked or didn't like about it. While some children indicated liking all of the commercials, children only seemed to critique the commercial for a toy of the opposite gender. Male interviewees saw Barbie very negatively. The boys knew very easily that Barbie was meant for girls. Females liked the Barbie commercial (worldtoys, 2015), but were not as equally critical of the Spider-Man commercial (Toys Videos, 2014). LEGO Friends (LEGO, 2014) was a better-received commercial by male children despite it being meant for females. However, the LEGO commercial was not as readily identified as a toy meant for girls. J ake who very strongly contested the Barbie commercial (worldtoys, 2015), especially the fact that Barbie was a superhero, knew LEGO Friends (LEGO,2014) were meant for girls but still said that he "loved girl LEGOs." Max thought there was a boy in the LEGO Friends commercial (LEGO, 2014) but it was actually just a girl with very short hair. This may have influenced him not disliking the commercial, but he still picked LEGO Creator. Spider-Man and TMNT were popular picks if the child either watched the shows or liked superheroes, which shows the importance of licensing agreements in the toy industry (Toys Videos, 2014; Playmates, 2015). Children were more excited to play with a toy product that they owned such as LEGOs or Barbie, which were common brands that the children owned. This matches the data found by Mintel, which can be seen in Figure 4. 


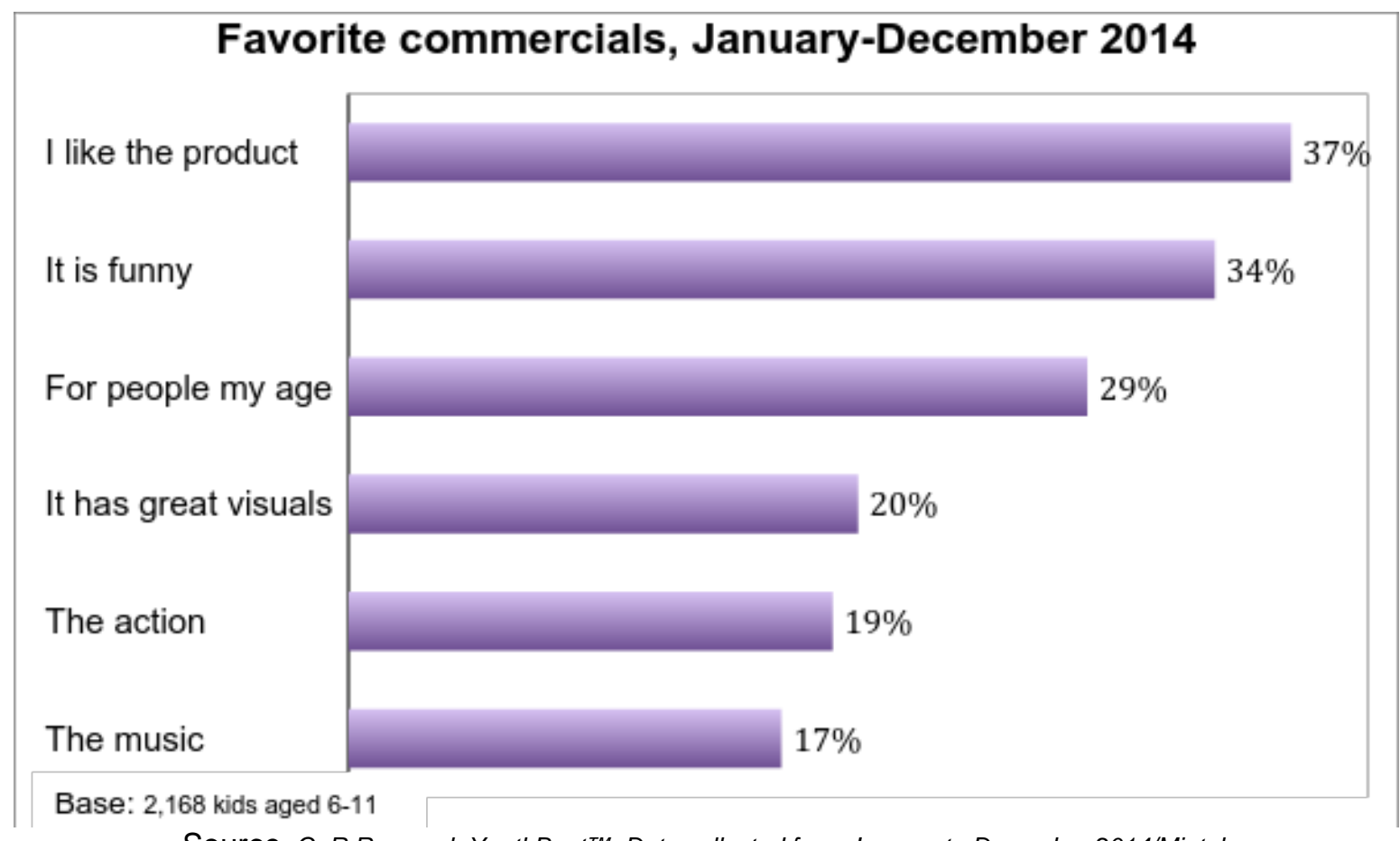

Source: C+R Research YouthBeat ${ }^{\mathrm{TM}}$. Data collected from January to December 2014/Mintel.

Figure 4: Favorite commercials, January-December 2014

\section{Toy Popularity}

The most common favorite toy among children in the survey was LEGO (See Figure 5). Ninety-three percent of parents said their children play with LEGOs or a similar product. There are different brands of LEGOs though such as LEGO Friends and LEGO Creator that are marketed gender specifically. The survey did not specify which brand of LEGOs the child preferred so further research would have to be done to clarify. In the interviews, there was no repetition of favorite toys mentioned. All interview participants owned LEGOs, though, further showing its popularity. This is interesting that despite the large popularity of LEGO, it is not the largest toy manufacturer. This may be due to its limited products in comparison to Mattel and Hasbro who own brands such as Fisher-Price, Tyco, Pleasant Company, Cranium, Inc., Milton Bradley, Tiger Electronics, Parker Brothers, Playskool, and Wizards of the Coast (Erwina, 2014). Six of the seven 
interview participants selected the gender appropriate set of LEGOs. Overall LEGOs are a popular toy preference and may indicate that children prefer the LEGO product that makes gender salient to them.

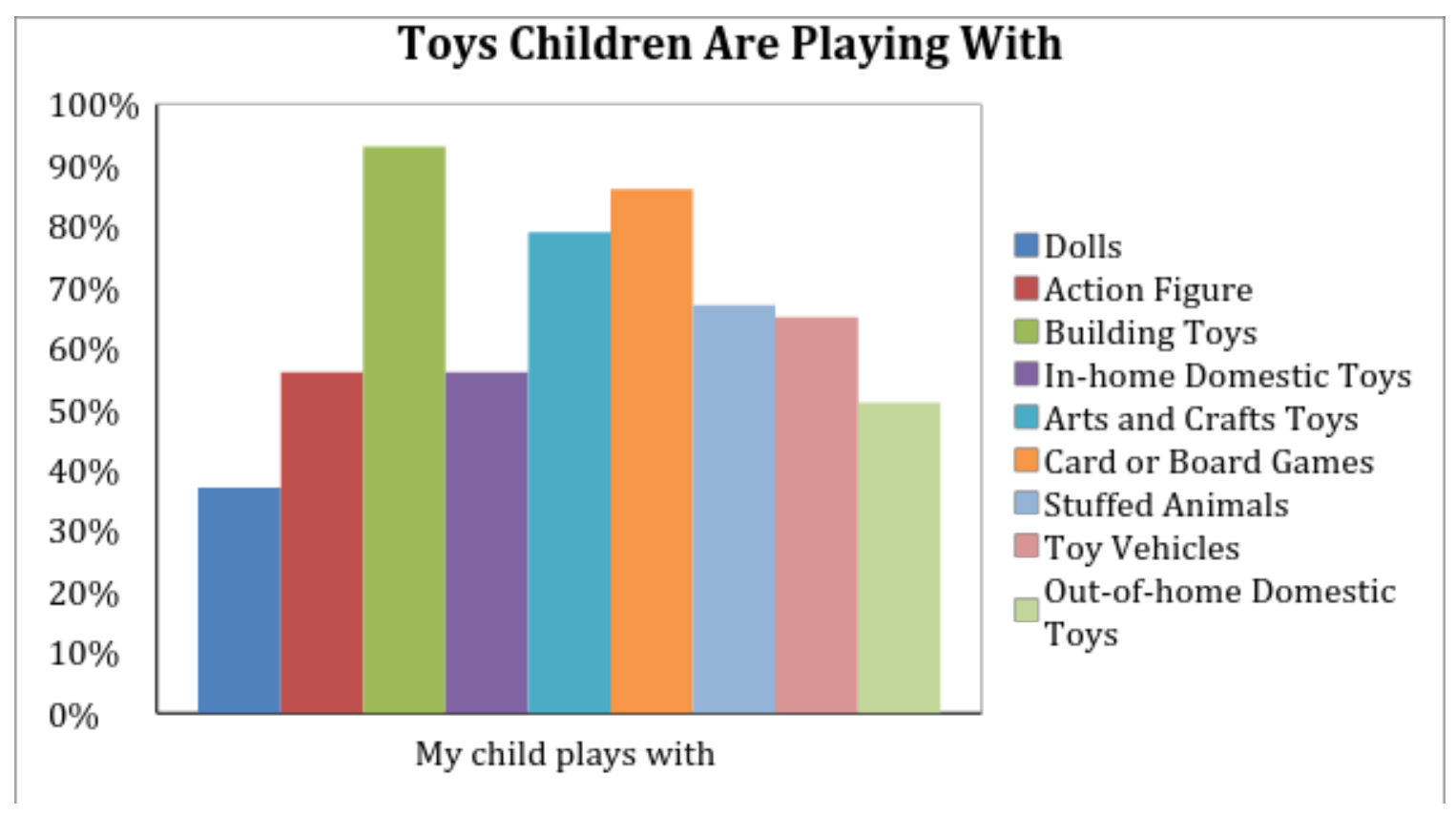

Figure 5: Toy's Children are Playing With $(n=59)$

Figure 6 shows that males are primarily playing with traditionally male toys such as action figures and toy vehicles, and females are playing with traditionally female toys such as dolls. Surprisingly in-home domestic toys do not seem to favor one gender over another. Gender-neutral toys such as building toys, card or board games, and arts and crafts are popular between both genders. Figure 7 also demonstrates how play is decreasing as a child gets older, with it being almost non-existent by the age of nine. 


\section{Toys Played With Based Off Gender}

\section{Dolls}

Out-of-Home Domestic Toys

Action Figures

In-Home Domestic Toys

Toy Vehicles

Stuffed Animals

Arts and Crafts Toys

Card or Board Games

Building Toys

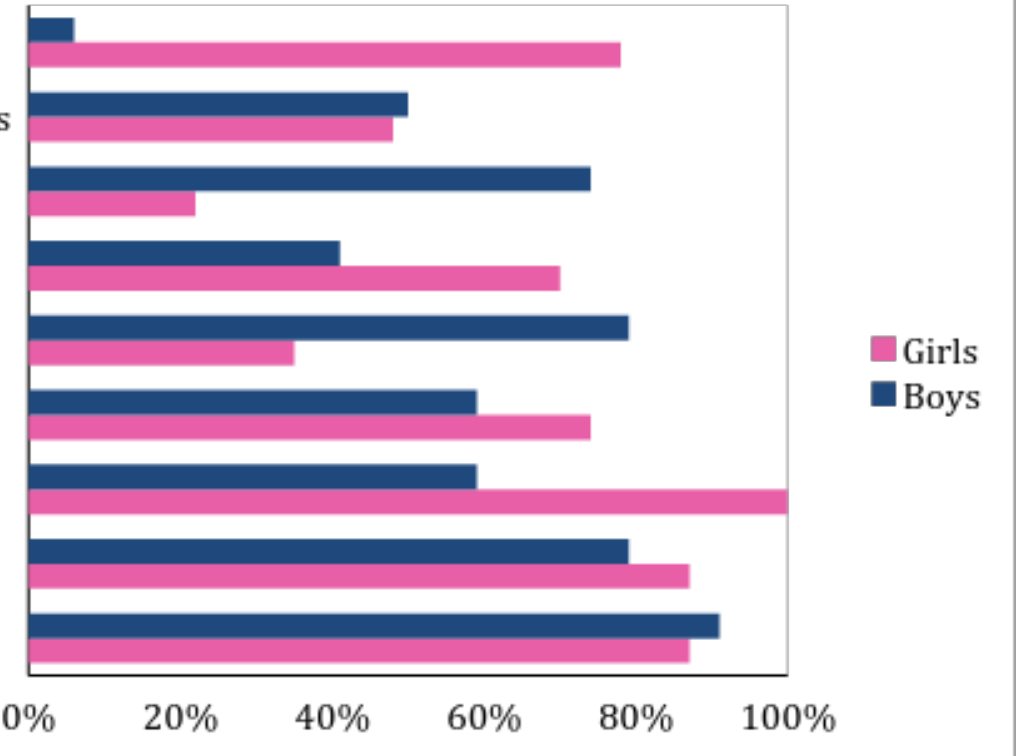

Figure 6: Toys Played With Based off Gender Base: Girls n=23, Boys n=34

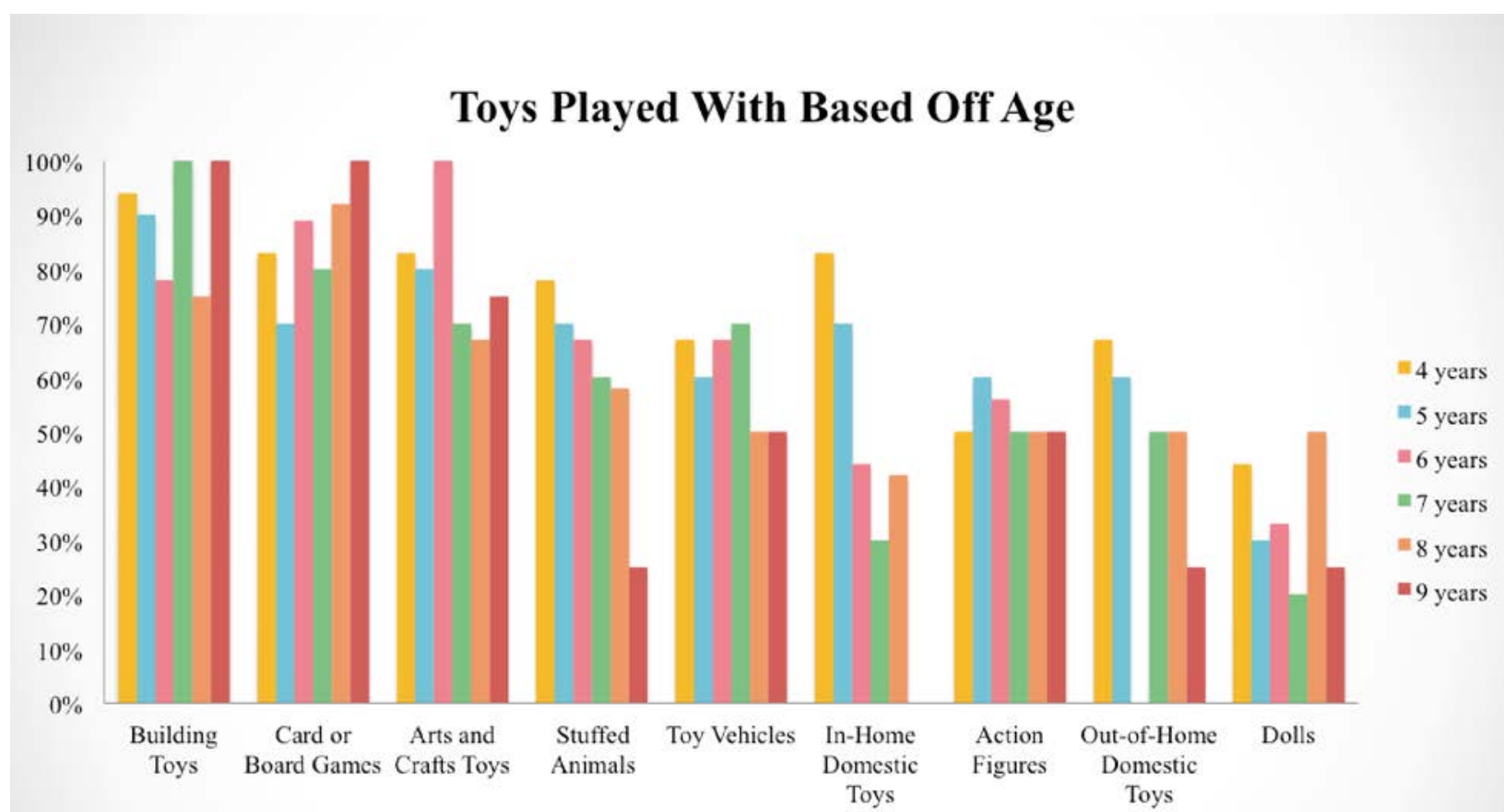

Figure 7: Toys Played With Based off Age, Base: 4 years $n=18,5$ years $n=10,6$ years $n=9,7$ years $n=10$, 8 years $n=12,9$ years $n=4$ 


\section{Discussion}

All three of my phases had a small sample; therefore, sample size is a strong limitation of my research. The findings I have made cannot be projected onto the larger population. This is also my first time conducting my own primary research; therefore, my skills as a moderator are limited. While it may have been the children's personality, or my lack of experience moderating, the children were very quiet and it was a challenge to get detailed responses.

In the future, I would ask children to point out which toys were meant for a boy and a girl and then have them watch a commercial to see if their opinions had changed. I would also like to better see how well children could point out a commercial during a television show by watching a show with them and asking them to point out the commercials to me. I also think an evaluation of toy commercials for the top grossing products would be helpful in understanding the different ways gender is being portrayed.

\section{Conclusion}

Overall, this research provides a strong foundation for a better understanding of the relationship between toy advertising and child gender identity. Consistent with previous research, this study did find that as a child gets older they better understand that a commercial is meant to persuade. This happens at about the age of nine, but by four they know that a commercial comes between their show. Children identify gender stereotypes in play, but seem open minded to allowing cross-gender playing while still choosing not to participate.

I think the best way to encourage cross-gender play with toys is to mix toy sections in 
stores such as having the Barbies next to the Hot Wheels, and then having board games rather than having Barbies, Bratz, and baby dolls all in the same aisle. Another way to combat this is to show cross-gender play in commercials since children mirror the behavior they see on-screen. It would be a process that would have multiple partners between toy manufacturers, toy retailers, advertising agents, and purchasers of toys but would ultimately result in children feeling more free to play with the toys they find most interesting and fun to them. 


\section{APPENDIX A}

Q1: Participation in this survey is completely voluntary. Participants may refuse to answer any questions and can stop at any time.

Surveys will remain completely anonymous. Risks of participating in this survey may include upset feelings about gender identity or parenting opinions. There are no right or wrong answers in this survey. Participation is greatly appreciated. After completing this survey please share on your own social media platforms. In addition to this survey I will be conducting child interviews. If you are interested in having your child interviewed please contact me at lauren.andreu@tcu.edu. By clicking I agree below you are consenting to participate in this survey.

a. Agree

b. Disagree

Q2: Do you have children?

a. Yes

b. No

Disqualify if No

Q3: Do you have a child between the ages of four and nine?

a. Yes

b. No

Disqualify if No

Q4: If you have more than 1 child between the age of 4-9 please select which child you will think of when answering the questions below by checking all appropriate boxes.

Boy, Girl, 4 years, 5 years, 6 years, 7 years, 8 years, 9 years

Q5: How many hours a week do your children watch TV on average?
a. None
b. Less than 1 hour
c. 1-2 hours
d. 3-4 hours
e. 5+ hours
f. I do not know TV amount

Q6: What media does your child utilize most often to watch TV?

a. Cable

b. Netflix

c. Online Streaming i.e. Hulu or network provider site

d. Network TV

e. Other (please list)

Q7: What are your child's top 3 favorite TV shows?

3 text boxes

Q8: Some television shows are marketed for children and while others are marketed for adults. Think about television shows or networks that are marketed for children are there any your child is not allowed to watch?
a. Yes
b. No
c. I'm not sure

Q8a: If yes what are they? 


\section{Text box}

Q9: Does your child ever discuss the difference between boys and girls with you? This can be biological differences or social differences.
a. Yes
b. No

Q9a: Can you give a description of a situation in which your child brought up the opposite sex with you?

Text box

Q10: Of your child's last 10 play dates how many were with/involved the opposite sex only?
a. $1-2$
b. 3-4
c. 5-6
d. $7-8$
e. $9-10$

Q11: What is your child's favorite toy? (If electronic such as WII or Xbox please specify game) Text box

Q12: Are there any toys you do not let your child play with?
a. Yes
b. No
c. I'm not sure

If a is selected then skip to $12 \mathrm{a}$, if b or c skip to 13

Q12a: If yes, what are they? Why are they not allowed to play with them?

Q13: Select which toy(s) your child plays with

Multi-response table

Options include dolls, action figures, building toys, in-home domestic toys, arts and crafts toys, card or board games, stuffed animals, toy vehicles, out-of-home domestic toys

Q14: On a scale of 1-10, 1 being highly unavailable and 10 being highly acceptable, how acceptable do you feel it is your child plays with the following toys?

Sliding scale, options are dolls, action figures, building toys, in-home domestic toys, arts and crafts toys, card or board games, stuffed animals, toy vehicles, out-of-home domestic toys Q15: Do you believe advertising strongly affects what toys your child wants to play with?
a. Yes
b. No
c. I'm not sure
d. Prefer not to answer

Q16: Are you male or female?
a. Male
b. Female
c. Prefer not to answer

Q17: How many children do you have?
a. 1
b. 2
c. 3
d. 4
e. $5+$

Q18: Please list the sex and age of children below 


\section{Text box}

Q19: What is your age range?
a. $18-25$
b. $26-34$
c. $35-44$
d. $45-54$
e. $55+$

Q20: What income level does your household fall into?
a. Less than $\$ 10,000$
b. $\$ 10,000-29,999$
c. $\$ 30,000-49,999$
d. $\$ 50,000-69,999$
e. $\$ 70,000-89,999$
f. $\$ 90,000-149,000$
g. $\$ 150,000$
h. Prefer not to answer

Q21: What is your current relationship status?
a. Married
b. Divorced
c. Single
d. Prefer not to answer 


\section{APPENDIX B}

\section{Interview Guide}

Word Association

Pink

Yellow

Green

Blue

Baby Doll

School

Action Figure

Puzzle

Toy kitchen

Nerf gun

Lego

Stuffed animal

Dress up

Smart

Fun

Sporty

1. How old are you?

2. What grade are you in?

3. Do you have any brothers or sisters? How old are they?

4. What is your favorite toy? Why? Can you show it to me? 
5. Do your siblings play with this toy too?

6. Do you know what a commercial or advertisement is?

7. We are going to watch some on my computer today and then we are going to get a chance to play with some of the toys we saw in them. How does that sound?

8. Okay so now what toy do you want to play with for a few minutes?

9. What did you think of $\mathrm{X}$ toy?

10. Have you ever wanted to play with this toy before?

11. At school when you are playing do the boys and girls play together?

a. What do the boys play?

b. What do the girls play?

12. Do girls play with toy cars? Why or why not?

13. Do boys play with dolls? Why or why not?

14. Do girls play with puzzles? Why or why not?

15. Do boys play with board or card games like UNO or monopoly? Why or why not?

16. How do you think your parents would feel if you played with cars? Dolls? Puzzles? Board games? 


\section{APPENDIX C}

\section{LEGO CREATOR:}

https://www.youtube.com/watch?v=V9VQLiqSqjk\&list=PLbl4zDZ4fGDj2h3o2wR4pVFe6jkest

$\underline{\mathrm{u} 0 \mathrm{t} \& \text { index }=8}$

\section{LEGO Friends:}

https://www.youtube.com/watch?v=spEv2iMyEYY\&index=9\&list=PLbl4zDZ4fGDj2h3o2wR4

pVFe6jkestu0t

\section{TMNT Figure:}

https://www.youtube.com/watch?v=DHhg5G500SM\&index=10\&list=PLbl4zDZ4fGDj2h3o2w

$\underline{\text { R4pVFe6jkestu0t }}$

Nerf Rebelle:

https://www.youtube.com/watch?v=n4VJ6hyQHso\&index=11\&list=PLbl4zDZ4fGDj2h3o2wR4

pVFe6jkestu0t

\section{Spider-Man Figure:}

https://www.youtube.com/watch?v=uoWKD2ad5vA\&index=13\&list=PLbl4zDZ4fGDj2h3o2wR

4pVFe6jkestu0t

\section{Barbie:}

Video has been deleted off YouTube but

https://www.youtube.com/watch?v=hVVSJUmcwJg\&feature=youtu.be

is very similar and uses the same Barbie product 


\section{APPENDIX D}

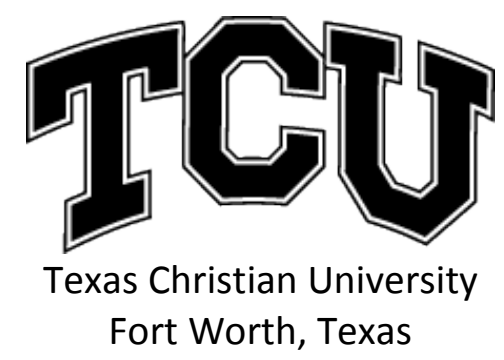

\section{PARENT'S PERMISSION TO PARTICIPATE IN RESEARCH}

Title of Research: Child Gender Identity and Advertising

\section{Funding Agency/Sponsor:}

Study Investigators: Lauren Andreu and Dr. Catherine Coleman

What is the purpose of the research? The purpose of the research is to better understand the effect advertising has on children forming their gender identity and the role advertising plays on adults who purchase items for children.

How many children will take part in this study? The goal is to interview about 6-8 children for this study.

What is my and my child's involvement for taking part in this study?

While participating in this study parent and child will go through an interview process. The interview process will include watching different commercials and observing play with different toys.

For how long is my child expected to be in this study, and how much of my child's time is required? The study will be conducted for a year and a half but each child is only expected to be interviewed once for about 40 minutes. A follow-up interview may be necessary.

What are the risks of taking part in this study and how will they be minimized? The risks of taking part in this study are emotional confusion. To minimize confusion the researcher will go over questions with parents prior to interview to get a better understanding of what the child already knows about sex and gender. Another risk is to bring up any upset feelings between child and parent. These risks will also be minimized through discussion with the parents. 
What are the benefits for taking part in the study? There are no direct benefits to participants for participating in this study.

Will I be compensated for taking part in the study? There will be no compensation for taking part in this study.

What is an alternate procedure(s) that I can choose instead of having my child take part in this study?

Instead of choosing to have your child participate in the study you can decline total participation or answer a few questions yourself.

How will my child's confidentiality be protected?

Actual names of participants will not be used and the true names will only be shared between the researcher and her professor.

Is my child's participation voluntary?

Yes, child's participation is voluntary.

Can my child stop taking part in this research?

Yes, all children can stop taking part in the research at any time.

What are the procedures for withdrawal?

Participants can withdraw at any time by notifying the researcher in the interview or after the interview process. Withdrawal is voluntary and is completely up to the participant. If the participant chooses to withdraw after the interview has been conducted they must notify the researcher by the end of October 2015.

Will I be given a copy of the permission document to keep?

Yes, parents will be given a copy of the permission document to keep.

Who should I contact if I have questions regarding the study?

If you have questions regarding the study please contact Lauren Andreu at 310-961-6560 or lauren.andreu@tcu.edu or Dr. Catherine Coleman at c.coleman@tcu.edu.

Who should I contact if I have concerns regarding my child's rights as a study participant?

Dr. Dan Southard, Chair, TCU Institutional Review Board, Phone 817 257-6869.

Dr. Bonnie Melhart, TCU Research Integrity Office, Telephone 817-257-7104.

Your signature below indicates that you have read or been read the information provided above, you have received answers to all of your questions and have been told who to call if you have any more questions, you have freely allowed your child to participate in this research, and you understand that you are not giving up any of your legal rights.

Child's Name (please print):

Date of birth:

Parent's Name (please print):

Parent's Signature:

Date:

Investigator's Signature:

Date: 


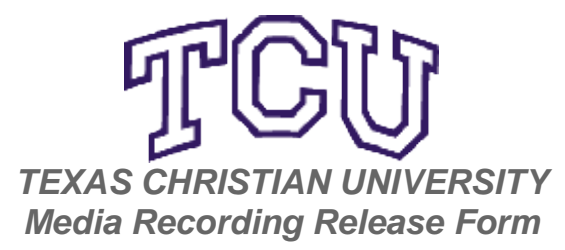

Title of Research: Child Gender Identity and Advertising

Study Investigators: Lauren Andreu and Dr. Catherine Coleman

Record types. As part of this study, the following types of media records will be made of you during your participation in the research:

- Audio Recording

Record uses. Please indicate what uses of the media records listed above you are willing to permit by initialing below and signing the form at the end. We will only use the media records in ways that you agree to.

- The media record(s) can be studied by the research team for use in this research project.

- The media records(s) and/or their transcriptions can be used for scientific or scholarly publications.

I have read the above descriptions and give my consent for the use of the media recordings as indicated by my initials above.

Name:

Signature:

Date:

If you have concerns regarding your rights as a study participant, contact Dr. Dan Southard, Chair, TCU Institutional Review Board, Phone 817 257-6869 or Dr. Bonnie Melhart, TCU Research Integrity Officer, Phone 817-257-7104. 


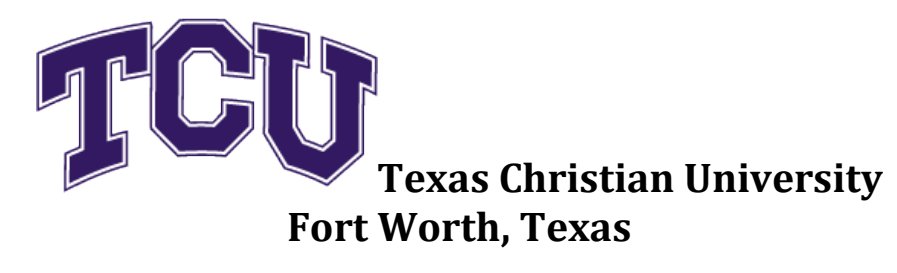

CONSENT TO PARTICIPATE IN RESEARCH

Title of Research: Child Gender Identity and Advertising

\section{Funding Agency/Sponsor:}

Study Investigators: Lauren Andreu and Dr. Catherine Coleman

What is the purpose of the research? The purpose of the research is to better understand the effect advertising has on children forming their gender identity and the role advertising plays on adults who purchase items for children.

How many people will participate in this study? The goal is to interview about 6-8 children for this study. As well as their parents and other adults who have daily interaction with children such as teachers or nannies. There will be about 12-16 interviews total.

What is my involvement for participating in this study?

While participating in this study adult and child will go through an interview process. The interview process will include watching different commercials and observing play with different toys.

How long am I expected to be in this study for and how much of my time is required? The study will be conducted for a year and a half but each child should be interviewed once for about 40 minutes. There is the possibility that a follow-up interview may be necessary.

What are the risks of participating in this study and how will they be minimized? The risks of taking part in this study is to be emotionally upset or confused. To minimize this risk participants will have the right to refuse to answer any question and will be debriefed post-interview.

What are the benefits for participating in this study?

There are no direct benefits to participants for participating in this study.

Will I be compensated for participating in this study? There will be no compensation for taking part in this study.

What is an alternate procedure(s) that I can choose instead of participating in this study?

There is no alternate procedure other than declining to participate in the study. 
How will my confidentiality be protected?

Actual names of participants will not be used and the true names will only be shared between the researcher and her professor.

Is my participation voluntary?

Yes, participation is voluntary.

\section{Can I stop taking part in this research?}

Yes, you may stop taking part in the research at any point during the research process.

\section{What are the procedures for withdrawal?}

Participants can withdraw at any time by notifying the researcher in the interview or after the interview process. Withdrawal is voluntary and is completely up to the participant. If the participant chooses to withdraw after the interview has been conducted they must notify the researcher by the end of October 2015.

Will I be given a copy of the consent document to keep?

Yes, you will be given a copy of the consent document to keep.

\section{Who should I contact if I have questions regarding the study?}

If you have questions regarding the study contact Lauren Andreu at 310-961-6560 or lauren.andreu@tcu.edu or Catherine Coleman at c.coleman@tcu.edu.

Who should I contact if I have concerns regarding my rights as a study participant? Dr. Dan Southard, Chair, TCU Institutional Review Board, Phone 817 257-6869.

Dr. Bonnie Melhart, TCU Research Integrity Office, Telephone 817-257-7104.

Your signature below indicates that you have read or been read the information provided above, you have received answers to all of your questions and have been told who to call if you have any more questions, you have freely decided to participate in this research, and you understand that you are not giving up any of your legal rights.

Participant Name (please print):

Participant Signature:

Date:

Investigator Name (please print):

Date:

Investigator Signature:

Date: 


\section{References}

Bakir, A., \& Palan, K. M. (2010). How are children's attitudes toward ads and brands affected by gender-related content in advertising? J ournal of Advertising, 39(1), 35-48.

Beales, J . H. (2004). Advertising to Kids and the FTC: A Regulatory Retrospective That Advises the Present. Retrieved from https:// www.ftc.gov/ sites/default/ files/documents/public_statements/ advertisi ng-kids-and-ftc-regulatory-retrospective-advises-present/ 040802adstokids.pdf

Blakemore, J . O., \& Centers, R. E. (2005). Characteristics of Boys' and Girls' Toys. Sex Roles, 53(9/ 10), 619-633. doi:10.1007/ s11199-005-7729-0

Blakemore, J . E., LaRue, A. A., \& Olejnik, A. B. (1979). Sex-appropriate toy preference and the ability to conceptualize toys as sex-role related. Developmental Psychology, 15(3), 339-340. doi:10.1037/ 0012-1649.15.3.339

Bonetto, L. 2015. Marketing to Kids- U.S - April 2015.Retrieved from Mintel database.

Busis, H. (2013). Hasbro introduces nerf rebelle line for girls, starting with the heartbreaker bow -- EXCLUSIVE. Retrieved from http:/ / www.ew.com/ article/ 2013/ 02/ 08/ hasbro-introduces-nerf-rebelle-linefor-girls-starting-with-the-heartbreaker-bow-exclusive

Butter, E. J., Popovich, P. M., Stackhouse, R. H., \&Garner, R. K. (1981). Discrimination of television programs and commercials by preschool children. J ournal of Advertising Research, 21(2), 53-56.

Communication. : Oxford University Press. Retrieved 14 Dec. 2015, from http:// www.oxfordreference.com/ view/ 10.1093/ acref/9780199568758.001.0001 /acref-9780199568758-e-0581. 
Chandler, D., \&amp; Munday, R.(2011). social learning theory. In A Dictionary of Media and Communication. : Oxford University Press. Retrieved 14 Dec. 2015, from http:// www.oxfordreference.com/ view/ 10.1093/ acref/ 9780199568758.001 .0001 /acref-9780199568758-e-2538.

(2014). Advertising to Children and Teens: Current Practices. Common Sense Media. Retrieved from commonsensemedia.org.

Erwina, I. 2014. Traditional Toys and Games- U.S. - April 2014. Retrieved from Mintel database.

Fisher-Thompson, D., \& Sausa, A. D. (1995). Toy Selection for Children: Personality and Toy Request Influences. Sex Roles, 33(3/4), 239-255.

Freeman, N. (2007). Preschoolers' Perceptions of Gender Appropriate Toys and their Parents' Beliefs About Genderized Behaviors: Miscommunication, Mixed Messages, or Hidden Truths?. Early Childhood Education J ournal, 34(5), 357366. doi:10.1007/s10643-006-0123-x

LEGO. (2014, May 26). LEGO Friends 30s TVC- J ungle 2014 [Video file]. Retrieved from

https:/ / www.youtube.com/ watch?v=spEv2iMyEYY\&index=9\&list=PLbl4zDZ4f GDj2h3o2wR4pVFe6jkestu0t

Levin, S. R., Petros, T. V., \& Petrella, F. W. (1982). Preschoolers' awareness of television advertising. Child Development, 53(4), 933-937. doi:10.2307/ 1129131

Macklin, M., \& Carlson, L. (1999). Advertising to children concepts and controversies. Thousand Oaks, California: Sage Publications.

Martin, C. L. (1990). Attitudes and expectations about children with nontraditional and traditional gender roles . Sex Roles, 22(3/4), 151. 
Martínez, E., Nicolás, M. Á., \& Salas, Á. (2013). Gender Representation in Advertising of Toys in the Christmas Period (2009-12). Comunicar, 21(41), 187-194. doi:10.3916/C41-2013-18

McLeod, S. (2007). Nature vs Nurture in Psychology. Retrieved from http:/ / www.simplypsychology.org/ naturevsnurture.html

Pike, J . J ., \&J ennings, N. A. (2005). The effects of commercials on Children's perceptions of gender appropriate toy use . Sex Roles, 52(1/2), 83. doi:0.1007/ s11199-005-1195-6

Playmates Toys. (2015, September 8). TMNT Half Shell Heroes Mutation Vehicles Commercial [Video file]. Retrieved from https:// www.youtube.com/ watch?v=DHhg5G5O0SM\&list=PLbl4zDZ4fGDj2h 3o2wR4pVFe6jkestu0t\&index $=10$

Nerf Rebelle Official. (2015, February, 25). Nerf Rebelle Secrets \& Spies/ Strongheart and Secret Shot [Video file]. Retrieved from https:// www.youtube.com/ watch?v=n4VJ 6hyQHso\&list=PLbl4zDZ4fGDj2h3o 2wR4pVFe6jkestu0t\&index $=11$

Toys R Us Singapore. (2014 March 6). LEGO Creator 3 in 1 - 31013, 31014, 31015, 31037, 31018 [Video file.] Retrieved from https:/ / www.youtube.com/ watch?v=V9VQLiqSqjk\&index=8\&list=PLbl4zDZ4f GDj2h3o2wR4pVFe6jkestu0t

Toys Videos. (2014, December 4). Hasbro Marvel Spider man Action Figures-1 [Video file]. Retrieved from https:/ / www.youtube.com/ watch?v=uoWKD2ad5vA\&list=PLbl4zDZ4fGDj2h3 o2wR4pVFe6jkestu0t\&index=13 
worldtoys. (2015,March 20). 2015 BARBIE in Princess Power "Super Sqaud" dolls Commercial [Video file]. Retrieved from https:// www.youtube.com/watch?v=hVVSJ UmcwJ g\&feature=youtu.be 